\title{
Interaction between Paracoccidioides brasiliensis conidia and the coagulation system: involvement of fibrinogen
}

\author{
Diana Tamayo', Orville Hernández ${ }^{1,2}$, Cesar Muñoz-Cadavid ${ }^{3}$, Luz Elena Cano ${ }^{3,4}$, Angel González ${ }^{4,5 /+}$ \\ ${ }^{1}$ Molecular and Cell Biology Unit ${ }^{3}$ Medical and Experimental Mycology Unit, Corporación para Investigaciones Biológicas, \\ Medellín, Colombia ${ }^{2}$ Facultad de Ciencias de la Salud, Institución Universitaria Colegio Mayor de Antioquia, Medellín, Colombia \\ ${ }^{4}$ Escuela de Microbiología ${ }^{5}$ Basic and Applied Microbiology Research Group, Universidad de Antioquia, Medellín, Colombia
}

The infectious process starts with an initial contact between pathogen and host. We have previously demonstrated that Paracoccidioides brasiliensis conidia interact with plasma proteins including fibrinogen, which is considered the major component of the coagulation system. In this study, we evaluated the in vitro capacity of $\mathrm{P}$. brasiliensis conidia to aggregate with plasma proteins and compounds involved in the coagulation system. We assessed the aggregation of $\mathrm{P}$. brasiliensis conidia after incubation with human serum or plasma in the presence or absence of anticoagulants, extracellular matrix (ECM) proteins, metabolic and protein inhibitors, monosaccharides and other compounds. Additionally, prothrombin and partial thromboplastin times were determined after the interaction of $\mathrm{P}$. brasiliensis conidia with human plasma. ECM proteins, monosaccharides and human plasma significantly induced P. brasiliensis conidial aggregation; however, anticoagulants and metabolic and protein inhibitors diminished the aggregation process. The extrinsic coagulation pathway was not affected by the interaction between $\mathrm{P}$. brasiliensis conidia and plasma proteins, while the intrinsic pathway was markedly altered. These results indicate that $\mathrm{P}$. brasiliensis conidia interact with proteins involved in the coagulation system. This interaction may play an important role in the initial inflammatory response, as well as fungal disease progression caused by $\mathrm{P}$. brasiliensis dissemination.

Key words: Paracoccidioides brasiliensis conidia - fibrinogen - coagulation system

Paracoccidioidomycosis (PCM) is an endemic and systemic mycosis recognised as a public health problem throughout Latin America, especially in Brazil, Colombia, Venezuela and Argentina (Restrepo et al. 2001, Colombo et al. 2011). The infection is caused by the inhalation of Paracoccidioides brasiliensis conidia, which usually causes a benign and transient pulmonary infection. In $90 \%$ of clinically active cases, PCM develops into a chronic, systemic and progressive disease that usually affects adult male farmers, while $10 \%$ of cases involving the clinically active form of PCM are reported as acute (or juvenile) infections. The lung is the primary infection site, but dissemination occurs regularly, with the appearance of secondary lesions in other organs and systems (Brummer et al. 1993, Restrepo et al. 2008).

As in other fungal infections (e.g., histoplasmosis, cryptococcosis, coccidioidomycosis and blastomycosis) (Klein \& Tebbets 2007), the mechanisms used by this fungal pathogen to cause infection and dissemination in the host are unclear, but during the initial interaction of $P$. brasiliensis conidia with host tissue components, both extracellular matrix (ECM) proteins and epithelial/endothe-

doi: $10.1590 / 0074-0276108042013015$

Financial support: CIB, CODI/Universidad de Antioquia/ Sustainability Strategy for Groups A1 and A (2011-2012), Fundacion para la Promocion de la Investigacion y la Tecnologia Banco de la Republica de Colombia (2050), COLCIENCIAS (2213-051-7586) + Corresponding author: angelgonzalezmarin1972@gmail.com Received 6 November 2012

Accepted 4 April 2013 lial cells are most likely involved (Patti \& Hook 1994, Caro et al. 2008, Gonzalez et al. 2008a). These interactions could also participate in the dissemination process. Nonetheless, various $P$. brasiliensis virulence factors have been described, such as extracellular enzymes capable of degrading host molecules (Puccia et al. 1998) and ECM component-binding molecules, including fibrinogen, fibronectin and laminin (Gonzalez et al. 2005).

The interaction of microorganisms with host components, including ECM proteins and cells, is an important mechanism that allows invasion, establishment, proliferation, tropism and immune response modulation. Moreover, amplification of the immune response could result in the activation of both coagulation system pathways, i.e., the "extrinsic", which depends on the release of tissue factor and the "intrinsic" (also known as the contact system) (Persson et al. 2003). During the infectious process, the intrinsic pathway is involved in regulating pro-inflammatory activity, host defence and disease severity. Several pathogens express molecules that interact with fibrinogen and plasminogen, the former considered the major plasma protein coagulation factor (Persson 2000, Aliberti et al. 2003, Persson et al. 2003).

Fibrinogen is a key component of the coagulation system and is also found in the ECM of damaged tissue. This plasma glycoprotein controls blood loss during tissue damage (Herrick et al. 1999, Flick et al. 2004). Fibrinogen is converted to fibrin by the action of thrombin during the coagulation cascade process, which appears to be important for pathogen containment; however, several microorganisms can overcome this process. In addition, the fibrinogen/fibrin deposits produced during the inflammatory process can be used by the pathogens to 
adhere to the mucosal surface (Simpson-Haidaris et al. 1998, Shenkman et al. 2000, Flock \& Flock 2001, Pietrocola et al. 2005). In our pulmonary PCM murine model, infected animals show increased ECM protein expression (mainly fibrinogen, fibronectin and laminin) in the lungs during the acute phase of infection (Gonzalez et al. 2008b). In addition, fibrinogen inhibits the adherence and internalisation of $P$. brasiliensis conidia in alveolar type II cells (Caro et al. 2008, Gonzalez et al. 2008a). This finding suggests a role for fibrinogen in fungal adherence to host tissues. All of the above reports suggest that both the adhesion and aggregation processes could be important in PCM pathogenesis.

In the present study, we evaluated the ability of $P$. brasiliensis conidia to aggregate with fibrinogen, as well as with different molecules involved in the coagulation system and other compounds present in human plasma. We also investigated the ability of the fungus to activate the coagulation system. The results of these aggregation assays indicate that fibrinogen and other proteins are involved in the interaction of $P$. brasiliensis conidia with the coagulation system. Moreover, incubation of $P$. brasiliensis conidia with human plasma resulted in the prolongation of the time needed to activate the intrinsic coagulation pathway. These interactions may play an important role in the initial inflammatory response, as well as in the progression of the fungal disease caused by $P$. brasiliensis dissemination.

\section{SUBJECTS, MATERIALS AND METHODS}

Fungal growth and conidia production - The $P$. brasiliensis isolate we used was ATCC 60855, which sporulates freely on water-agar (Bacto-agar DIFCO, Detroit, MI, USA). The procedures for growing mycelia in a chemically defined medium and for collecting and dislodging conidia were performed as reported previously (Restrepo \& Jimenez 1980, Restrepo et al. 1986). The conidia were counted in a haemocytometer and their viability was determined using fluorescein diacetate and ethidium bromide staining (Calich et al. 1979).

Reagents - The bovine fibrinogen, human fibronectin, immunochemicals and reagents employed in this study were obtained from Sigma Chemical Co (Poole, Dorset, UK), unless otherwise specified. In addition, a monoclonal antibody (mAb2G4) against the 32-kDa protein from $P$. brasiliensis was produced as previously described (Gonzalez et al. 2005) and was used to treat the conidia suspension. A mouse isotype IgG1 was used as the control at a dilution of 1:100 (Table).

Plasma and serum sources - Blood samples were drawn from healthy volunteers $(n=6)$ into Vacutainer tubes (Becton-Dickinson) either without anticoagulants or with 1:9 volumes of $129 \mathrm{mM}$ sodium citrate, $\mathrm{pH} 7.4$, to obtain serum or plasma, respectively. Blood was centrifuged at 2,500 $\mathrm{g}$ for $15 \mathrm{~min}$. The pellet was removed and the serum and plasma samples were stored at $-20^{\circ} \mathrm{C}$.

Aggregation assays - To evaluate the ability of $P$. brasiliensis conidia to aggregate and the mechanism involved in this aggregation process, $10^{7}$ conidia were resuspended in $250 \mu \mathrm{L}$ of phosphate buffered saline (PBS), human serum or plasma and incubated for $3 \mathrm{~h}$ at $37^{\circ} \mathrm{C}$. A number of different compounds, including EMC proteins (fibrinogen and fibronectin), metabolic inhibitors, monosaccharides, glycosaminoglycans, anticoagulants, serine protease inhibitors and protein folding inhibitors were also added, as detailed in Table. After incubation, conidia were washed three times with PBS and counted

TABLE

Compounds used in Paracoccidioides brasiliensis conidia aggregation assays

\begin{tabular}{lcc}
\hline Group & Compound & Concentration \\
\hline Extracellular matrix proteins & Fibrinogen & $500 \mu \mathrm{g} / \mathrm{mL}$ \\
& Fibronectin & $500 \mu \mathrm{g} / \mathrm{mL}$ \\
Metabolic inhibitors & Thimerosal & $0.02 \%$ \\
& Cycloheximide & $10 \mu \mathrm{g} / \mathrm{mL}$ \\
& Sodium azide & $1 \mathrm{mM}$ \\
Monosaccharides & N-acetylneuraminic acid & $200 \mathrm{mM}$ \\
& Glucose & $200 \mathrm{mM}$ \\
Glycosaminoglycans & Glucosamine & $200 \mathrm{mM}$ \\
Anticoagulants & Dextran sulphate & $10 \mu \mathrm{g} / \mathrm{mL}$ \\
Serine protease inhibitors & Heparin & $1 \mathrm{UI} / \mathrm{mL}$ \\
& H-D-Pro-Phe-Arg-chloromethyl ketone & $50 \mu \mathrm{g} / \mathrm{mL}$ \\
Antibodies & Leupeptin & $10 \mathrm{mM}$ \\
Protein-folding inhibitor & Phenylmethylsulphonyl fluoride & $50 \mu \mathrm{g} / \mathrm{mL}$ \\
\hline
\end{tabular}


in a haemocytometer. The aggregation percentage was established according to the free conidia number in comparison with initial inoculum.

Clotting assays - Clotting time was measured in a coagulometer (Coag-A-Mate ${ }^{\circledR}$ XM, Organon Teknika, Durham, USA). Approximately $10^{7}$ P. brasiliensis conidia were re-suspended in $250 \mu \mathrm{L}$ of plasma and incubated for $3 \mathrm{~h}$ at $37^{\circ} \mathrm{C}$. After incubation, conidia were removed by centrifugation $(7,000 \mathrm{~g}, 2 \mathrm{~min})$ and the supernatant filtered using $0.22 \mu \mathrm{m}$ filters. To investigate the intrinsic coagulation pathway [activated partial thromboplastin time (aPTT) assay], $100 \mu \mathrm{L}$ of reagent APTT (APTT kit, bioMérieux, Inc Durham, NC, USA) was incubated with $100 \mu \mathrm{L}$ of supernatant for $5 \mathrm{~min}$ at $37^{\circ} \mathrm{C}$ in the coagulometer followed by the addition of $100 \mu \mathrm{L} 25 \mathrm{mM} \mathrm{CaCl}_{2}$. The extrinsic pathway of coagulation [prothrombin time (PT) assay] was studied by adding $200 \mu \mathrm{L}$ of Simplastin Excel S (bioMérieux) to $100 \mu \mathrm{L}$ supernatant in the coagulometer at $37^{\circ} \mathrm{C}$ and the clot-forming time was measured.

Statistical analysis - The results are expressed as the mean \pm standard error of the means of three independent experiments. The data were analysed by ANOVA and Student's $t$ test using GraphPad Prism, version 4.0 for Macintosh (GraphPad Software, San Diego, California, USA). Values of $p<0.05$ were considered statistically significant.

\section{RESULTS}

Human plasma and serum induce P. brasiliensis conidia aggregation - To determine if the proteins present in both human plasma and serum could induce $P$. brasiliensis conidia aggregation, we incubated fungal propagules with plasma or serum as described in the Subjects, Materials and Methods section. We observed that both human serum and plasma induced conidial aggregation, with plasma inducing the higher aggregation and PBS treatment resulting in minimal aggregation (Fig. 1A, B). We subsequently used human plasma to determine the effects of several compounds involved in the coagulation system.

ECM proteins and carbohydrates enhance conidial aggregation capability - As observed in Fig. 1C, the addition of exogenous ECM proteins, such as fibrinogen and fibronectin, increased aggregation when PBS or human plasma and serum were used. Moreover, the addition of monosaccharides, including glucose, glucosamine or $\mathrm{N}$-acetylneuraminic acid, increased aggregation when either plasma or PBS was present (Fig. 2A).

Protease inhibitors, metabolic inhibitors, proteinfolding inhibitors and anticoagulantcompounds decrease conidial aggregation capability - When either protease inhibitors or metabolic inhibitors [mainly thimerosal and phenylmethylsulphonyl fluoride (PMSF)], were added to human plasma, a significant decrease in conidial aggregation was observed (Fig. 2B, C). Moreover, the addition of Congo red (a colorant that alters the secondary structure of proteins) to plasma also decreased conidial aggregation (Fig. 3A).
The addition of dextran, heparin or the peptide $\mathrm{H}$ D-Pro-Phe-Arg-chloromethyl ketone to plasma (all anticoagulants) significantly decreased the aggregation process $(\mathrm{p}<0.001)$ (Fig. 3B, C).

No alteration in conidial aggregation was observed when a specific $\mathrm{mAb}$ was used against a hydrolase family molecule that recognises fibrinogen and fibronectin and is implicated in the fungal adherence process (data not shown).

P. brasiliensis conidia alter the intrinsic coagulation pathway - Due to the ability of $P$. brasiliensis conidia to bind fibrinogen and to further investigate the interaction of this fungus with the contact system, the effects of $P$. brasiliensis on both intrinsic (aPTT) and extrinsic (PT) coagulation pathways were examined. We observed that plasma from healthy individuals who were previously subjected to incubation with $P$. brasiliensis conidia

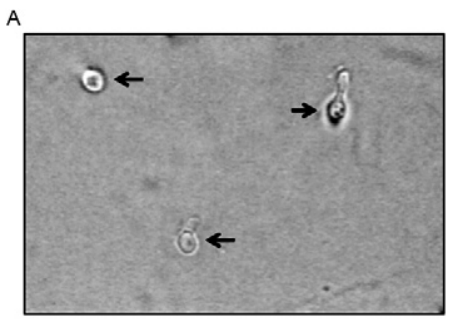

B
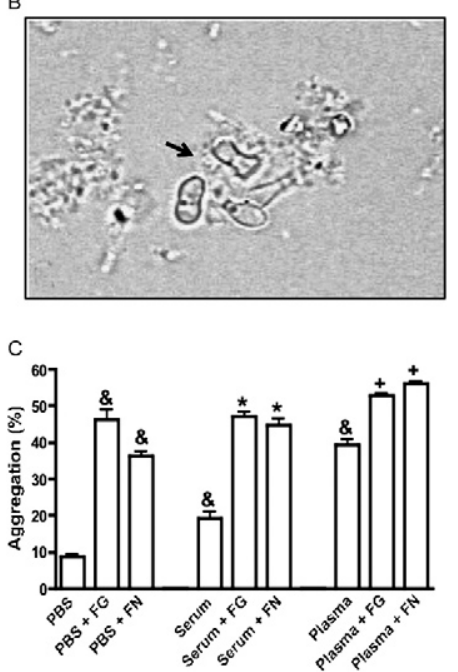

Fig. 1: Paracoccidioides brasiliensis conidial aggregation induced by plasma and serum is enhanced by extracellular matrix proteins. Microscopic evaluation of $P$. brasiliensis conidial aggregation in the presence of phosphate buffered saline (PBS) (A) or human plasma (B). Arrows in A indicate free conidia and arrow in B indicates conidial aggregation. Magnifications: 100X. C: P. brasiliensis conidial aggregation determined by incubating fungal propagules with human plasma or serum in presence or absence of soluble proteins [fibrinogen (FG) and fibronectin (FN)]. Fungal cells were counted with a haemocytometer and the aggregation percentage established according to the free conidia number in comparison to initial inocula. Results expressed as mean \pm standard error of the means of three independent experiments. $\&: \mathrm{p}<0.001$ when compared to PBS; *: $\mathrm{p}<0.001$ when compared to serum; + : $p<0.001$ when compared to plasma. 
showed an altered aPTT, indicating that this fungus affected the intrinsic coagulation pathway. However, the PT was not altered (Fig. 4).

\section{DISCUSSION}

Fibrinogen is considered one of the most important plasma proteins in the coagulation and inflammation processes. Fibrin clots produced by the interaction of fibrinogen with thrombin during the activation of the contact system allow for pathogen containment by creating a barrier to the surrounding tissue and preventing invasion and dissemination (Levi et al. 2004). Furthermore, during the establishment of the infectious process, pathogens must overcome many other immune response processes, including activation of the contact system, which results in the initiation of the intrinsic coagulation pathway (Risberg et al. 1991). Nevertheless, over-activation of the contact system could be deleterious to the host and would
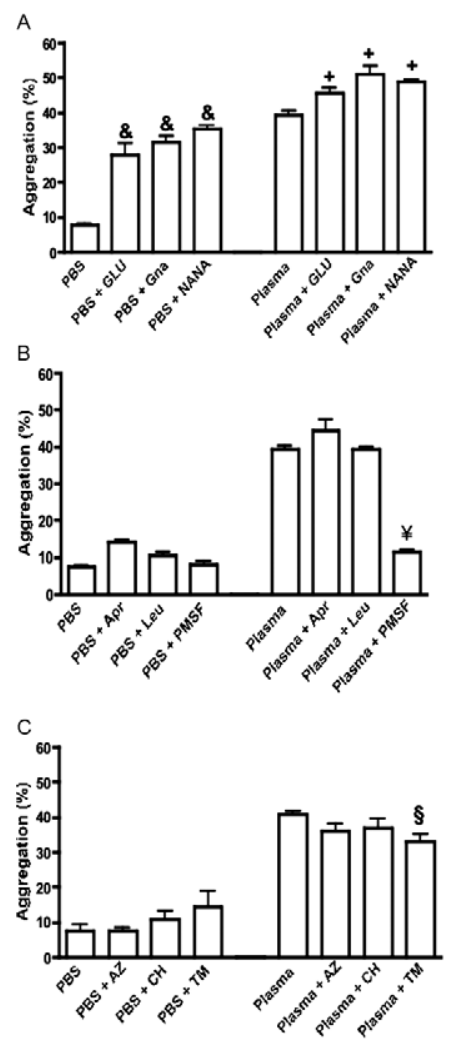

Fig. 2: effect of monosaccharides, serine proteases and metabolic inhibitors on Paracoccidioides brasiliensis conidial aggregation. P. brasiliensis conidial aggregation determined by incubating fungal propagules with human plasma in presence or absence of monosaccharides [glucose (GLU), glucosamine (Gna) and N-acteyl neuroaminic acid (NANA)] (A), serine protease inhibitors [aprotinin (Apr), leupoptin (Leu) and phenylmethylsulfonyl fluoride (PMSF)] (B) and metabolic inhibitors [sodium azide (AZ), cicloheximide (CH) and timerosal (TM)] (C). Fungal propagules counted with a haemocytometer and aggregation percentage established according to the free conidia number in comparison to initial inocula. Results expressed as mean \pm standard error of the means of three independent experiments. $\&: \mathrm{p}<0.001$ when compared to phosphate buffered saline (PBS); $+: \mathrm{p}<0.001$ when compared to plasma; $¥$ : $\mathrm{p}<0.001 ; \S: \mathrm{p}<0.05$ when compared to plasma. be an important factor in the pathogenicity of invading organisms as a consequence of increased vascular permeability, which enables organisms to access and colonise other host tissues. Additionally, the pathogen could activate the contact system and thereby modulate the host immune response for its own benefit (Murphy et al. 2011), e.g., by the induction of a hypocoagulative state in the infectious focus to avoid entrapment by the fibrin network.

$P$. brasiliensis binds to fibrinogen, an ECM protein overexpressed in the lungs of mice infected with this fungal pathogen; this interaction is mediated by adhesins expressed on its own surface (Gonzalez et al. 2005, 2008a, b). Additionally, in vitro studies have demonstrated that this fungal pathogen has the ability to degrade ECM proteins, including fibrinogen (Puccia et al. 1998), an effect that may inhibit or prevent containment of the fungal pathogen by the coagulation system. Thus, the above virulence factors exhibited by $P$. brasiliensis may promote colonisation and widespread dissemination via the circulatory system.

The coagulation system is believed to play an important role in the homeostasis process because it is involved in the response to injurious stimuli and pathogen invaders
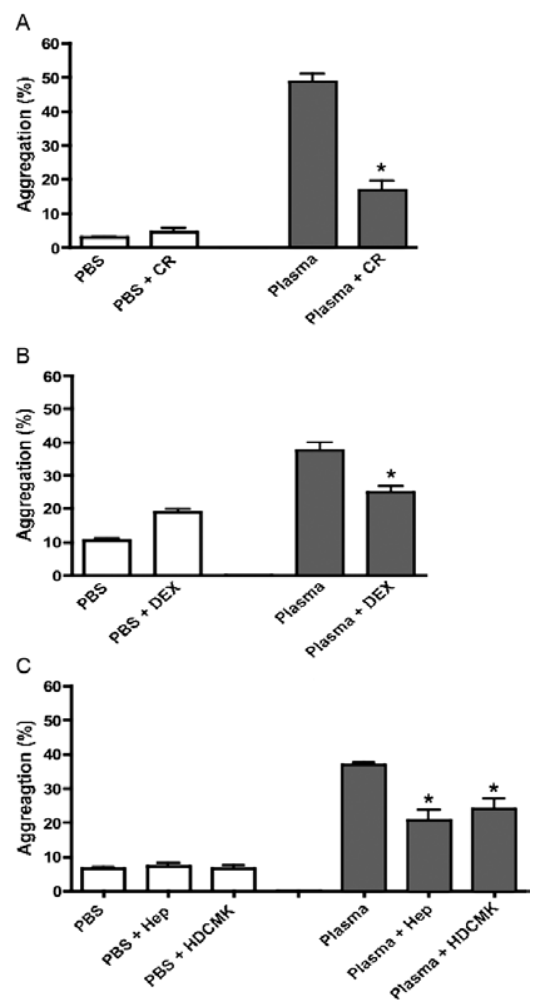

Fig. 3: effect of a folding protein inhibitor or anticoagulants on Paracoccidioides brasiliensis conidial aggregation. P. brasiliensis conidial aggregation determined by incubating fungal propagules with human plasma in presence or absence of Congo red (CR) (A), dextran (DEX) (B) and anticoagulants [heparin (Hep) and H-D-Pro-Phe-Arg-chloromethyl ketone (HD-CMK)] (C). Fungal cells counted with a haemocytometer and aggregation percentage established according to the free conidia number in comparison to initial inocula. Results expressed as the mean \pm standard error of the means of three independent experiments. Asterisk means $\mathrm{p}<0.001$ when compared to plasma. 
(Choi et al. 2006). Human plasma contains coagulation factors that can stimulate the aggregation process of some microorganisms, including fungal pathogens; this process could facilitate pathogen adhesion to host cells with subsequent tissue invasion (Amara et al. 2008). In the present study, $P$. brasiliensis conidia aggregated in the presence of human plasma, suggesting that certain proteins, including fibrinogen and other coagulation factors, may not only facilitate fungal adhesion to the host tissue, but may also initiate the activation of the contact system.

In the aggregation assays, we observed that the addition of exogenous fibrinogen and fibronectin, as well as monosaccharides such as glucose, glucosamine and $\mathrm{N}$-acetylneuraminic acid, enhanced the aggregation process observed with plasma alone. Thus, monosaccharides might have an impact on the binding of plasma proteins to outer membrane-anchored fungal proteins or adhesins present on the fungal surface. However, the addition of thimerosal (a metabolic inhibitor), PMSF (a serine protease inhibitor) or Congo red dye (a protein folding inhibitor) to human plasma significantly diminished conidial adhesion and aggregation. Similar results were reported by Rauceo et al. (2004), who expressed the Candida albicans adhesin Als5p in Saccharomyces cerevisiae to study its effects on adhesion of fungal cells to fibronectin and on cellular aggregation. They observed that fungal cells expressing Alsp5 in the presence of galactose induced adhesion and aggregation, whereas in the presence of agents that perturbed protein secondary structure (e.g., Congo red), they inhibited the adhesion and aggregation processes. The above results are consistent with the idea that adhesins on the surface of $P$. brasiliensis conidia undergo a conformational shift to form ordered domains on the fungal surface in cellular aggregates and, furthermore, that the conidial aggregation process depends on cellular metabolic activity.

However, medically important fungi have the ability to interact with and activate the coagulation contact system (Jong et al. 2003, Nogueira et al. 2010). Once activated, the contact system is involved in regulating homeostatic and inflammatory processes (Oehmcke \& Herwald 2010). In the present study, P. brasiliensis

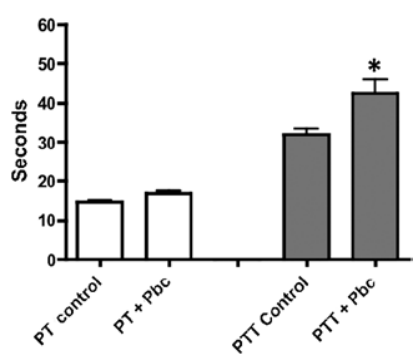

Fig. 4: effect of Paracoccidioides brasiliensis conidia ( $\mathrm{Pbc})$ on the intrinsic and extrinsic pathways of coagulation. P. brasiliensis conidia incubated with human citrated plasma for $3 \mathrm{~h}$ at $37^{\circ} \mathrm{C}$. Fungal cells removed and resulting plasma supernatants analysed by clot formation assays. Data are representative of experiments using plasma from six different volunteers, each done in duplicate. PT: prothrombin. Asterisk means $\mathrm{p}<0.001$ when compared to partial thromboplastin time (PTT) control. conidia were incubated with human plasma to determine if this fungal pathogen could trigger the coagulation cascade. After incubation, the fungal propagules were removed and the resulting supernatants were analysed in aPTT and PT assays. The conidia of P. brasiliensis caused a significant delay in the clotting time for the intrinsic pathway (aPTT), but not the extrinsic pathway (PT). Thus, the binding of fibrinogen and contact factors to $P$. brasiliensis conidia results in the depletion of these proteins in plasma and causes a hypocoagulatory state. Prolongation of clot formation is a sign of deficiency of coagulation factors, indicating less available contact-phase proteins and fibrinogen (Ponjee et al. 1991). These results suggest that $P$. brasiliensis is capable of activating the contact system and that these mechanisms contribute to both the initial adhesion process and dissemination mechanism. More studies are needed to determine whether degradation of fibrinogen or release of other factors is involved in the coagulation process.

Antithrombin (AT) is the major inhibitor of coagulation proteases (Rau et al. 2007). A fraction of the circulating AT associates with blood vessel walls by binding to glycosaminoglycans such as dextran sulphate, resulting in its activation (Olson et al. 1981). This theory supports our finding that dextran sulphate inhibited $P$. brasiliensis conidia aggregation, most likely by inhibiting coagulation factors. Similar results were observed following the addition of the anticoagulants heparin and H-D-Pro-Phe-Arg-CMK, which resulted in the inhibition of $P$. brasiliensis conidial aggregation. Interestingly, the administration of H-D-Pro-Phe-Arg-CMK to mice infected with Salmonella prevents the severe pulmonary lesions caused by this bacterium, suggesting that the inhibition of contact system activation could be used to treat severe infectious diseases (Persson et al. 2000).

Adhesin-mediated microbial adherence is a key mechanism in the colonisation, establishment and dissemination of pathogenic fungi (Patti \& Hook 1994). Furthermore, P. brasiliensis expresses adhesin molecules on its own surface, allowing adhesion to ECM proteins and host cells (Gonzalez et al. 2005, 2008a, Caro et al. 2008, Donofrio et al. 2009, Nogueira et al. 2010). One of these molecules is a $32-\mathrm{kDa}$ molecule that belongs to an HAD superfamily that confers to P. brasiliensis the capacity to bind to fibrinogen and other ECM proteins (Gonzalez et al. 2005, 2008a). As described in the Subjects, Materials and Methods section, we used a mAb against this adhesin and we were surprised to observe that $P$. brasiliensis conidial aggregation was not altered by the addition of this antibody (data not shown). This result indicates that the $32-\mathrm{kDa}$ adhesin is not responsible for the $P$. brasiliensis conidial aggregation process and that other molecules on the fungal surface must be involved.

Taken together, these results appear to suggest that $P$. brasiliensis conidia are able to recognise the soluble proteins present in plasma, especially fibrinogen, as well as other factors involved in the coagulation system and these interactions may result in the depletion of plasma proteins, leading to hypocoagulation. The latter may contribute to the pathogenic inflammatory process observed in PCM. These interactions may also be important in adherence to 
host cells and the subsequent dissemination that occurs in the pathogenesis of PCM. Finally, the above results open the door to exploring the use of coagulation system inhibitors as a novel therapeutic approach to PCM.

\section{REFERENCES}

Aliberti J, Viola JP, Vieira-de-Abreu A, Bozza PT, Sher A, Scharfstein J 2003. Cutting edge: bradykinin induces IL-12 production by dendritic cells: a danger signal that drives Th1 polarization. J Immunol 170: 5349-5353.

Amara U, Rittirsch D, Flierl M, Bruckner U, Klos A, Gebhard F, Lambris JD, Huber-Lang M 2008. Interaction between the coagulation and complement system. Adv Exp Med Biol 632: 71-79.

Brummer E, Castaneda E, Restrepo A 1993. Paracoccidioidomycosis: an update. Clin Microbiol Rev 6: 89-117.

Calich VL, Purchio A, Paula CR 1979. A new fluorescent viability test for fungi cells. Mycopathologia 66: 175-177.

Caro E, Gonzalez A, Munoz C, Uran ME, Restrepo A, John Hamilton A, Cano LE 2008. Recognition of laminin by Paracoccidioides brasiliensis conidia: a possible mechanism of adherence to human type II alveolar cells. Med Mycol 46: 795-804.

Choi G, Schultz MJ, Levi M, van der Poll T 2006. The relationship between inflammation and the coagulation system. Swiss Med Wkly 136: 139-144.

Colombo AL, Tobón A, Restrepo A, Queiroz-Telles F, Nucci M 2011. Epidemiology of endemic systemic fungal infections in Latin America. Med Mycol 49: 785-798.

Donofrio FC, Calil AC, Miranda ET, Almeida AM, Benard G, Soares CP, Veoloso SN, Soares CM, Mendes-Giannini MJ 2009. Enolase from Paracoccidioides brasiliensis: isolation and identification as a fibronectin-binding protein. J Med Microbiol 58: 706-713.

Flick MJ, Du X, Witte DP, Jirouskova M, Soloviev DA, Busuttil SJ, Plow EF, Degen JL 2004. Leukocyte engagement of fibrin(ogen) via the integrin receptor alphaMbeta2/Mac-1 is critical for host inflammatory response in vivo. J Clin Invest 113: 1596-1606.

Flock M, Flock JI 2001. Rebinding of extracellular adherence protein Eap to Staphylococcus aureus can occur through a surface-bound neutral phosphatase. J Bacteriol 183: 3999-4003.

Gonzalez A, Caro E, Munoz C, Restrepo A, Hamilton AJ, Cano LE 2008a. Paracoccidioides brasiliensis conidia recognize fibronectin and fibrinogen which subsequently participate in adherence to human type II alveolar cells: involvement of a specific adhesin. Microb Pathog 44: 389-401.

Gonzalez A, Gomez BL, Diez S, Hernandez O, Restrepo A, Hamilton AJ, Cano LE 2005. Purification and partial characterization of a Paracoccidioides brasiliensis protein with capacity to bind to extracellular matrix proteins. Infect Immun 73: 2486-2495.

Gonzalez A, Lenzi HL, Motta EM, Caputo L, Restrepo A, Cano LE 2008b. Expression and arrangement of extracellular matrix proteins in the lungs of mice infected with Paracoccidioides brasiliensis conidia. Int J Exp Pathol 89: 106-116.

Herrick S, Blanc-Brude O, Gray A, Laurent G Fibrinogen 1999. Int J Biochem Cell Biol 31: 741-746.

Jong AY, Chen SHM, Stins MF, Kim KS, Tuan TL, Huang SH 2003. Binding of Candida albicans enolase to plasmin(ogen) results in enhanced invasion of human brain microvascular endothelial cells. J Clin Microbiol 52: 615-622.

Klein BS, Tebbets B 2007. Dimorphism and virulence in fungi. Curr Opin Microbiol 10: 314-319.

Levi M, van der Poll T, Buller HR 2004. Bidirectional relation between inflammation and coagulation. Circulation 109: 2698-2704.
Murphy EC, Mörgelin M, Cooney JC, Frick IM 2011. Interaction of Bacteroides fragilis and Bacteroides thetaiotaomicron with the kallikrein-kinin system. Microbiology 157: 2094-2105.

Nogueira SV, Fonseca FL, Rodrigues ML, Mundodi V, Abi-Chacra EA, Winters MS, Alderete JF, Soares CMA 2010. Paracoccidioides brasiliensis enolase is a surface protein that binds plasminogen and mediates interaction of yeast forms with host cells. Infect Immun 78: 4040-4050.

Oehmcke S, Herwald H 2010. Contact system activation in severe infectious diseases. $J$ Mol Med 88: 121-126.

Olson ST, Srinivasan KR, Bjork I, Shore JD 1981. Binding of high affinity heparin to antithrombin III. Stopped flow kinetic studies of the binding interaction. $J$ Biol Chem 256: 11073-11079.

Patti JM, Hook M 1994. Microbial adhesins recognizing extracellular matrix macromolecules. Curr Opin Cell Biol 6: 752-758.

Persson E 2000. Structure of human coagulation activated factor VII. Blood Coagul Fibrinolysis 11: S15-S17.

Persson K, Mörgelin M, Lindbom L, Alm P, Björck L, Herwald H 2000. Severe lung lesions caused by Salmonella are prevented by inhibition of the contact system. J Exp Med 192: 1415-1424.

Persson K, Russell W, Morgelin M, Herwald H 2003. The conversion of fibrinogen to fibrin at the surface of curliated Escherichia coli bacteria leads to the generation of proinflammatory fibrinopeptides. J Biol Chem 278: 31884-31890.

Pietrocola G, Schubert A, Visai L, Torti M, Fitzgerald JR, Foster TJ, Reinscheid DJ, Speziale P 2005. FbsA, a fibrinogen-binding protein from Streptococcus agalactiae, mediates platelet aggregation. Blood 105: 1052-1059.

Ponjee GA, Vader HL, de Wild PJ, Janssen GW, van der Graaf F 1991. One-step chromogenic equivalent of activated partial thromboplastin time evaluated for clinical application. Clin Chem 37: $1235-1244$.

Puccia R, Carmona AK, Gesztesi JL, Juliano L, Travassos LR 1998. Exocellular proteolytic activity of Paracoccidioides brasiliensis: cleavage of components associated with the basement membrane. Med Mycol 36: 345-348.

Rau JC, Beaulieu LM, Huntington JA, Church FC 2007. Serpins in thrombosis, hemostasis and fibrinolysis. $J$ Thromb Haemost 5 (Suppl.): S102-S115.

Rauceo JM, Gaur NK, Lee KG, Edwards JE, Klotz SA, Lipke PN 2004. Global cell surface conformational shift mediated by a Candida albicans adhesin. Infect Immun 72: 4948-4955.

Restrepo A, Benard G, de Castro CC, Agudelo CA, Tobon AM 2008. Pulmonary paracoccidioidomycosis. Semin Respir Crit Care Med 29: 182-197.

Restrepo A, Jimenez BE 1980. Growth of Paracoccidioides brasiliensis yeast phase in a chemically defined culture medium. J Clin Microbiol 12: 279-281.

Restrepo A, McEwen JG, Castaneda E 2001. The habitat of Paracoccidioides brasiliensis: how far from solving the riddle? Med Mycol 39: 233-241.

Restrepo A, Salazar ME, Cano LE, Patino MM 1986. A technique to collect and dislodge conidia produced by Paracoccidioides brasiliensis mycelial form. J Med Vet Mycol 24: 247-250.

Risberg B, Andreasson S, Eriksson E 1991. Disseminated intravascular coagulation. Acta Anaesthesiol Scand 35 (Suppl.): 60-71.

Shenkman B, Rubinstein E, Tamarin I, Dardik R, Savion N, Varon D 2000. Staphylococcus aureus adherence to thrombin-treated endothelial cells is mediated by fibrinogen but not by platelets. $J$ Lab Clin Med 135: 43-51.

Simpson-Haidaris PJ, Courtney MA, Wright TW, Goss R, Harmsen A, Gigliotti F 1998. Induction of fibrinogen expression in the lung epithelium during Pneumocystis carinii pneumonia. Infect Immun 66: 4431-4439. 